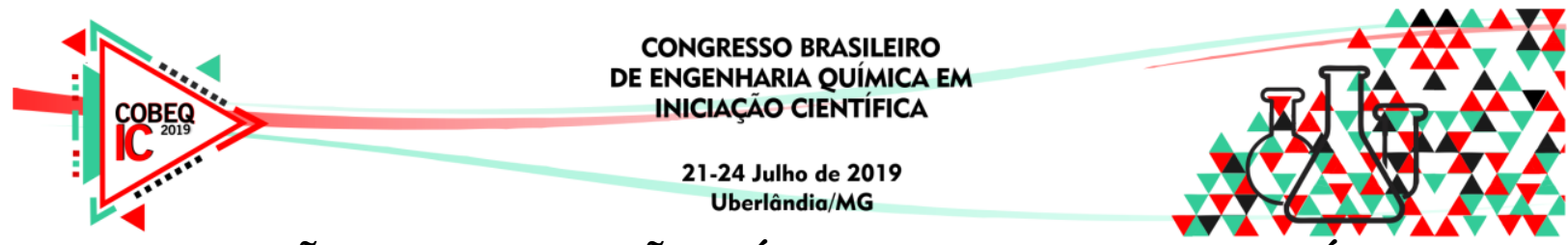

\title{
OBTENÇÃO E AVALIAÇÃO FÍSICA DE FILMES BIOPLÁSTICOS DE PECTINA COM ADIÇÃO DE FIBRAS DE MESOCARPO DO COCO-DA-BAÍA (Cocos nucifera) SECO
}

\author{
A. A. ROCHA ${ }^{1}$, L. C. PAIXÃO ${ }^{2}$, A. K. S. RAPOSO ${ }^{2}$, H. L. BRITO ${ }^{2}$, A. A. SANTANA ${ }^{1}$ \\ ${ }^{1}$ Universidade Federal do Maranhão, Departamento de Engenharia Química \\ ${ }^{2}$ Universidade Federal do Maranhão, Coordenação do Curso de Bacharelado Interdisciplinar em \\ Ciência e Tecnologia \\ E-mail para contato: adonesalmeida02@gmail.com
}

\begin{abstract}
RESUMO - Objetivou-se neste estudo desenvolver filmes compósitos de pectina com adição de fibras do mesocarpo de coco-da-baía seco (Cocos nucifera) em escala laboratorial. Os filmes foram preparados pela metodologia de casting em diferentes formulações, aplicando um Delineamento Composto Central Rotacional, utilizando glicerol como agente plastificante e cloreto de cálcio como agente reticulante. As fibras passaram por um pré-tratamento com $\mathrm{NaOH} 5 \%(\mathrm{~m} / \mathrm{m})$. O efeito do tratamento das fibras não ficou evidente sobre as propriedades físicas relacionadas a estas substâncias. O aumento da concentração de fibras tornou os compósitos menos permeáveis, porém quando as fibras não eram adicionadas, eles se tornavam muito higroscópicos, apresentando alta solubilidade. A partir das análises estatísticas determinaram-se as melhores formulações: $9 \mathrm{~g}$ de pectina/ $2 \mathrm{~g}$ de fibras e 5 gramas de pectina/0,5 gramas de fibras.
\end{abstract}

\section{INTRODUÇÃO}

Bioplásticos, biofilmes ou ainda filmes, são polímeros de origem natural, formados basicamente por materiais de origem vegetal ou animal. A pectina é um polissacarídeo muito usado na indústria alimentícia, obtida a partir da casca e bagaço de frutos cítricos (resíduos agrícolas) e possui boas propriedades para produção de bioplástico devido a sua alta solubilidade, propriedades de gelificação, alta biocompatibilidade e modificação química simples (Santana e Kieckbusch, 2013; Lopes et al., 2017).

Bioplásticos produzidos com pectina têm sido desenvolvidos, obtendo-se bons resultados para as propriedades físico-químicas, como as de barreira, denotados em alguns trabalhos (Seixas et al., 2013; Silva et al., 2009; Lopes et al., 2017; LaraEspinoza et al., 2018). A fim de melhorar as propriedades mecânicas, tem se incorporado a estes materiais, fibras lignocelulósicas, produzindo compósitos e nanocompósitos de bom desempenho mecânico (Machado et al., 2014).

Desta forma, percebe-se que os compostos mostrados tem potencial para o compósito polimérico, dado que objetiva-se encontrar o aumento das propriedades mecânicas e de barreira do material. Assim, no presente trabalho, estudou-se a influência das diferentes concentrações de fibras e pectina, usando glicerol como agente plastificante e adicionando-se cloreto de cálcio como agente reticulante, dado o bom comportamento destes materiais na literatura (Seixas et al., 2013; Silva et al., 2009; Lopes et al., 2017, Lara-Espinoza, 2018). 


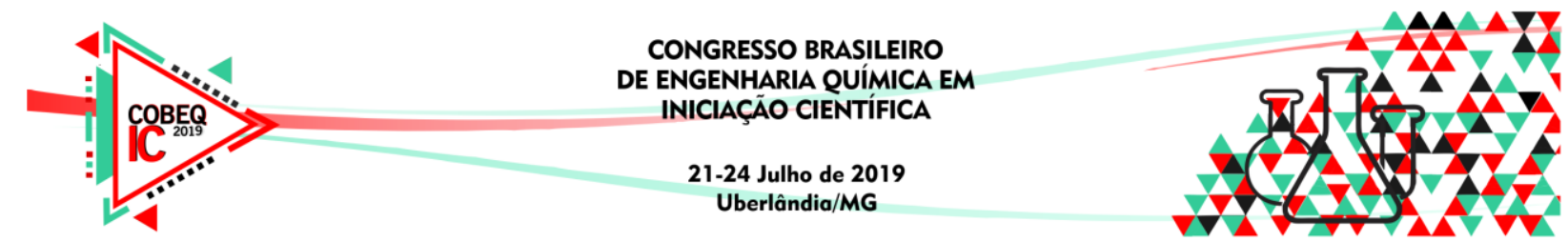

\section{MATERIAL E MÉTODO}

\subsection{Material e tratamento das fibras de coco-da-baía seco}

Pectina cítrica (Cpkelco, Limeira, Brasil), glicerol (Merck, Darmstadt, Alemanha), cloreto de cálcio dihidratado (Synth, Diadema, Brazil) e fibras do mesocarpo do coco-da-baía obtidas em um sítio local (São Luís - MA, Brasil), foram usados no desenvolvimento dos bioplásticos. Usou-se também $\mathrm{NaOH}$ para o prétratamento das fibras.

As fibras foram retiradas manualmente do coco-da-baía seco e lavadas em abundância com água a fim de remover as sujidades mais grosseiras. Para separar as fibras do restante do material foi usado um triturador industrial (Modelo DPM-2, Nogueira, São Paulo, Brasil) do Laboratório de Ensino e Pesquisa de Engenharia Química da UFMA (LEPEQ-COEQ-UFMA). As fibras foram cortadas com comprimento de $3 \mathrm{~cm}$ em média e secas a $60^{\circ} \mathrm{C}$ em estufa (Nova Técnica, modelo 400 $1 \mathrm{ND}$, Brasil) por 24h. Para o tratamento, adaptou-se a metodologia da literatura (Machado et al., 2014; Kalia et al., 2009; Huang, 2009), onde as fibras foram submersas em solução de $\mathrm{NaOH} 5 \%$ por 24 horas, em seguida lavadas por filtração com água em abundância a fim de retirar os resíduos de $\mathrm{NaOH}$, mantendo o $\mathrm{pH} 7$ para denotar a ausência da alcalinidade. Após o procedimento, as fibras foram secas novamente, a $60^{\circ} \mathrm{C}$ em estufa (Nova Técnica, modelo 400-1ND, Brasil) por 24h. Em seguida, foram submetidas à moagem em moinhos de martelos (Modelo 460*600, Yongsheng, China) e peneiradas em peneira vibratória a 120 Mesh (Tyler, EUA).

\subsection{Preparação do bioplásticos}

Foram preparados bioplásticos de acordo com a metodologia usada por Santana e Kieckbusch (2013) com adaptações. Usando-se agitador mecânico tipo "Turrax" (Quimis, modelo Q250-2, São Paulo, Brasil) para solubilização em água (400 mL), por 30 minutos, das concentrações de pectina e fibras e $3 \mathrm{~mL}$ de glicerol. Em seguida aqueceu-se a solução até $50^{\circ} \mathrm{C}$ e adicionou-se $30 \mathrm{~mL}$ de solução $1 \%$ de $\mathrm{CaCl}_{2} \cdot 2 \mathrm{H}_{2} \mathrm{O}$ lentamente. Os filmes foram obtidos através da metodologia de casting, controlando-se a massa de $100 \mathrm{~g}$ em placas de vidro (área: $172,03 \mathrm{~cm}^{2}$ ). Em seguida, estes foram secos em estufa (Nova Técnica, modelo 400-1ND, Brasil) por 24h, e armazenados em dessecadores com UR $\cong 50 \%$ para posteriores caracterizações.

\subsection{Planejamento experimental e avaliação física}

Os planejamentos experimentais foram utilizados para estudar os efeitos das variáveis de concentração de pectina e de fibras. Os intervalos estudados de concentrações foram definidos através dos ensaios preliminares. Foi realizado um delineamento composto central rotacional (DCCR), com pontos centrais (nível 0) e pontos axiais (níveis $\pm \alpha$ ), totalizando 11 ensaios (Tabela 1).

Os bioplásticos foram caracterizados quanto à espessura ( $\delta$ ), usando-se um micrômetro digital (modelo MDC-25S, Mitutoyo, Japão) com resolução de 0,01 mm e tomando cinco medidas em diferentes pontos simétricos. O conteúdo de umidade $(\omega)$ foi feito por gravimetria com auxílio de uma estufa (Nova Técnica, modelo 400-1ND, 


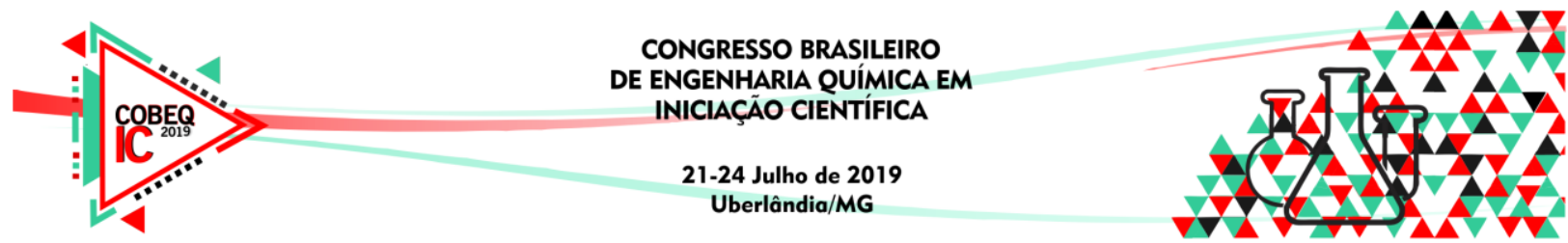

Brasil), a $105^{\circ} \mathrm{C}$ por $24 \mathrm{~h}$, de acordo com a metodologia apresentada por Rhim e colaboradores (2002). A umidade foi determinada em triplicata para cada formulação e expressa em fração mássica. A solubilidade em água (S) foi determinada em triplicata como proposto por Irissin-Mangata e colaboradores (2001). Massas determinadas de cada bioplásticos foram imersas em $50 \mathrm{~mL}$ de água destilada e colocada sob constante agitação em uma mesa de agitação (modelo 3545-40-EA, Termo Fisher SciInc, EUA) por $24 \mathrm{~h}$ a temperatura ambiente. Em seguida, o material foi colocado para secagem em estufa (Nova Técnica, modelo 400-1ND, Brasil), durante $24 \mathrm{~h}$ a $105^{\circ} \mathrm{C}$. A Permeabilidade a vapor de água (PVA) foi realizada pelo método gravimétrico, de acordo com a metodologia E96-96 (ASTM, 2016) usando potes de acrílico com cloreto de cálcio anidro a fim de se manter a umidade dentro do pote de aproximadamente $0 \%$. Os bioplásticos foram cuidadosamente colocados sob o pote, que, por sua vez, foi colocado em outro frasco, contendo uma solução de $\mathrm{NaCl}$ (Synth, São Paulo, Brasil) no fundo, para manter a umidade relativa de $75 \%$, obtendo-se uma diferença na pressão de vapor. A taxa de aumento na massa total do filme foi obtida através de medidas monitoradas durante $72 \mathrm{~h}$, encontrando-se a taxa de permeabilidade de água através do filme. Os valores de PVA foram obtidos usando a equação abaixo:

$$
P V A=\left[\frac{G \delta}{A_{e} \Delta P_{a}}\right]
$$

Onde, $\delta$ é a espessura do filme (mm), $\mathrm{A}_{\mathrm{e}}$ é a área exposta do filme $\left(\mathrm{m}^{2}\right), \Delta \mathrm{P}_{\mathrm{a}}$ é a pressão parcial de água através do filme $(\mathrm{kPa}), \mathrm{G}$ é a taxa de permeabilidade de água (g/dia), calculada através de regressão linear da relação de massa por tempo.

\subsection{Análises Estatísticas}

Os resultados das caracterizações físicas foram avaliados estatisticamente através da análise de Variância, aplicando o teste de Tukey ao nível de 5\% de significância. Os resultados do delineamento composto central rotacional foram avaliados com a finalidade de assegurar a validade dos coeficientes dos modelos obtidos dentro de um nível de confiança de 95\%, através de análises estatísticas apropriadas. Após a análise estatística dos coeficientes, foi realizada uma análise de variância (ANOVA), que consiste na avaliação do coeficiente de determinação $\left(R^{2}\right)$ e do teste $F$, verificando se o modelo apresenta um ajuste adequado aos dados experimentais. Para isso, foi utilizado o software Statistica 9.0 (Statsoft, Tulsa, EUA).

\section{RESULTADOS E DISCUSSÃO}

Na Tabela 1 são apresentados os resultados em relação à espessura, conteúdo de umidade, solubilidade em água e permeabilidade a vapor de água para o planejamento estudado.

Para a análise estatística, foram calculados a estimativa dos efeitos sobre as respostas estudadas, o erro padrão, o coeficiente $t$ e a significância estatística ( $p$-valor). Na Tabela 2 são encontrados os efeitos dos fatores lineares, quadráticos e das interações das respostas analisadas, assim como o $\mathrm{F}$ calculado, o $\mathrm{F}$ tabelado e o coeficiente de determinação, $\mathrm{R}^{2}$. Após a eliminação dos fatores não-significativos, verificou-se a significância da regressão e da falta de ajuste a um nível de significância de 5\%, através de uma Análise de Variância (ANOVA), utilizando o teste F para o planejamento experimental estudado. 
Tabela 1- Espessura $(\delta)$, conteúdo de umidade $(\omega)$, solubilidade em água $(\mathrm{S})$ e permeabilidade a vapor de água (PVA) para os bioplásticos de pectina com fibras de coco-da-baía tratados quimicamente com $\mathrm{NaOH} 5 \%(\mathrm{~m} / \mathrm{m})$.

\begin{tabular}{|c|c|c|c|c|c|c|}
\hline \multirow[b]{2}{*}{ Ensaios } & \multicolumn{2}{|c|}{ In natura ou tratadas } & \multicolumn{4}{|c|}{ In natura } \\
\hline & Pectina (g) & Fibras (g) & $\begin{array}{c}\boldsymbol{\delta} \\
(\mathbf{m m})\end{array}$ & $\begin{array}{c}\omega \\
(\%)\end{array}$ & $\begin{array}{c}\mathbf{S} \\
(\%) \\
\end{array}$ & PVA* \\
\hline 1 & 6 & 0,5 & $0,25 \pm 0,06^{\text {ab }}$ & $28,54 \pm 0,03^{\mathrm{a}}$ & $35,16 \pm 1,72^{\text {abcd }}$ & $111,05 \pm 0,86^{\mathrm{ab}}$ \\
\hline 2 & 9 & 0,5 & $0,22 \pm 0,04^{\mathrm{ab}}$ & $18,66 \pm 0,05^{\mathrm{a}}$ & $51,76 \pm 3,19^{\text {cd }}$ & $7,75 \pm 0,88^{\mathrm{a}}$ \\
\hline 3 & 6 & 2,5 & $0,48 \pm 0,09^{\mathrm{b}}$ & $25,31 \pm 0,05^{\mathrm{a}}$ & $46,60 \pm 0,98^{\mathrm{bcd}}$ & $22,41 \pm 7,61^{\mathrm{bc}}$ \\
\hline 4 & 9 & 2,5 & $0,41 \pm 0,04^{\mathrm{b}}$ & $19,94 \pm 0,01^{\mathrm{a}}$ & $31,87 \pm 5,49^{\text {abcd }}$ & $24,10 \pm 3,58^{\mathrm{bc}}$ \\
\hline 5 & 5 & 1,5 & $0,35 \pm 0,01^{\mathrm{ab}}$ & $35,75 \pm 0,11^{\mathrm{a}}$ & $85,04 \pm 4,70^{\mathrm{e}}$ & $20,08 \pm 1,84^{\mathrm{bc}}$ \\
\hline 6 & 10 & 1,5 & $0,43 \pm 0,07^{\mathrm{b}}$ & $10,93 \pm 0,05^{\mathrm{a}}$ & $17,02 \pm 2,10^{\mathrm{a}}$ & $16,91 \pm 0,86^{\mathrm{b}}$ \\
\hline $7^{\#}$ & 7,5 & 0 & $0,14 \pm 0,02^{\mathrm{a}}$ & $36,11 \pm 0,19^{\mathrm{a}}$ & $56,98 \pm 26,11^{\mathrm{d}}$ & $8,11 \pm 1,44^{\mathrm{a}}$ \\
\hline 8 & 7,5 & 3 & $0,69 \pm 0,07^{\mathrm{c}}$ & $22,30 \pm 0,03^{\mathrm{a}}$ & $31,09 \pm 5,49^{\text {abc }}$ & $56,21 \pm 3,25^{\mathrm{c}}$ \\
\hline 9 & 7,5 & 1,5 & $0,30 \pm 0,20^{\mathrm{ab}}$ & $29,11 \pm 0,04^{\mathrm{a}}$ & $21,16 \pm 2,45^{\mathrm{ab}}$ & $22,98 \pm 4,90^{\mathrm{bc}}$ \\
\hline 10 & 7,5 & 1,5 & $0,35 \pm 0,07^{\mathrm{ab}}$ & $29,35 \pm 0,03^{\mathrm{a}}$ & $26,52 \pm 1,13^{\mathrm{ab}}$ & $22,98 \pm 3,51^{\mathrm{bc}}$ \\
\hline 11 & 7,5 & 1,5 & $0,41 \pm 0,07^{\mathrm{ab}}$ & $23,24 \pm 0,05^{\mathrm{a}}$ & $25,09 \pm 4,04^{\mathrm{ab}}$ & $26,17 \pm 0,56^{\mathrm{bc}}$ \\
\hline
\end{tabular}

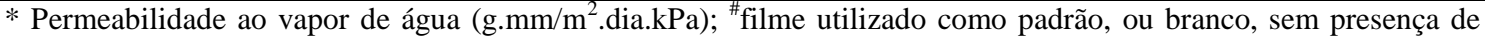
fibras;Média \pm desvio padrão;Médias com a mesma letra em cada coluna indicam que não há diferença significativa $(\mathrm{p}<0,05)$ pelo teste de Tukey.

Tabela 2- Coeficiente de regressão e valores de $\mathrm{R}^{2}$ para os modelos obtidos.

\begin{tabular}{|c|c|c|c|c|}
\hline Coeficiente de Regressão & $\delta(\mathbf{m m})$ & $\omega(\%)$ & S (\%) & PVA* \\
\hline \multicolumn{5}{|l|}{ Constante } \\
\hline$\beta_{\mathrm{O}}$ & 0,367 & 25,385 & 23,922 & 25,742 \\
\hline \multicolumn{5}{|l|}{ Linear } \\
\hline$\beta_{1}$ & - & $-6,295$ & $-11,790$ & - \\
\hline$\beta_{2}$ & 0,144 & - & $-5,632$ & 11,966 \\
\hline \multicolumn{5}{|l|}{ Quadrática } \\
\hline$\beta_{1}^{2}$ & - & - & 12,005 & $-5,554$ \\
\hline$\beta_{2}{ }^{2}$ & - & - & 8,511 & - \\
\hline \multicolumn{5}{|l|}{ Interações } \\
\hline$\beta_{12}$ & - & - & $-7,832$ & - \\
\hline$F_{\text {calculado }}$ & 31,890 & 11,737 & 1,842 & 13,288 \\
\hline $\mathrm{F}_{\text {tabulado }}$ & 5,120 & 5,120 & 5,050 & 4,460 \\
\hline$R^{2}$ & 0,788 & 0,566 & 0,648 & 0,777 \\
\hline \multicolumn{5}{|c|}{$\delta_{2}(\mathrm{~mm})=0,367+0,106 \mathrm{~F}$} \\
\hline
\end{tabular}

* Permeabilidade ao vapor de água (g. $\mathrm{mm} / \mathrm{m}^{2}$.dia. $\left.\mathrm{kPa}\right)$; - Efeitos não significativo ao nível $<5 \%$; $\mathrm{R}^{2}$ : coeficiente de determinação do modelo (indica a porcentagem de variabilidade ocorrida em cada modelo); $\beta_{i}$ : coeficiente de regressão estimado para os efeitos lineares; $\beta_{i}{ }^{2}$ : coeficiente de regressão estimado para os efeitos quadráticos; $\beta_{i j}$ : coeficiente de regressão estimado para os efeitos de interações; $i=1$ : concentração de pectina; $i=2$ : concentração de fibras; $\mathrm{P}$ e F representam as variáveis concentração de pectina e concentração de fibras, respectivamente. 


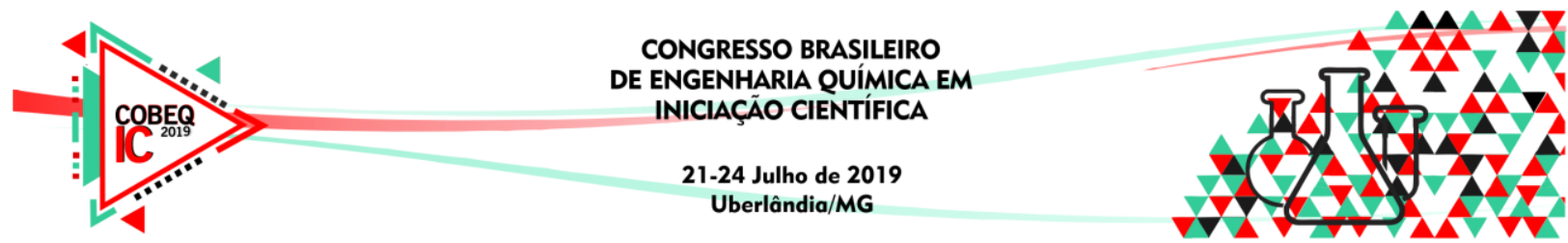

Percebeu-se que, devido a certa irregularidade nos diâmetros das fibras usadas, formulações com maiores quantidades, tiveram maiores desvios para as caracterizações de espessura e PVA (por exemplo, ensaio 8). Diferente do mostrado em filmes adicionados de nanocelulose (Ortiz et al., 2018; Machado et al., 2014; Rosa et al., 2010), as propriedades de barreira em geral não tiveram uma diminuição significativa, mas obteve-se resultados dentro dos valores para filmes de pectina (Lopez et al., 2017; Ngo et al., 2018). Pode-se afirmar que a adição das fibras nas dimensões utilizadas não ocasionou uma boa dispersão e não foram criados caminhos tortuosos que impedissem a passagem de água através do filme. Quanto solubilidade em água, observou-se que a adição das fibras ocasionou uma leve diminuição da mesma, podendo ser explicado pelo fato das fibras criarem um arranjo estrutural que estabiliza o bioplástico, deixando menos suscetível a solubilização, como observado por Ortiz e colaboradores (2018) encontraram resultados semelhantes para filmes de proteína de soja incorporada a celulose microfibrilada.

Estatisticamente, a espessura e PVA linear foram influenciados pela concentração de fibras, apresentando efeitos positivos. Os modelos codificados propostos para representá-los são descritos pelas equações apresentadas na Tabela 2. Os modelos apresentaram regressão significativa ao nível de $95 \%$ de confiança $\left(\mathrm{F}_{\text {calculado }}>\mathrm{F}_{\text {tabelado }}\right)$ e falta de ajuste não-significativa a este mesmo nível de confiança $\left(\mathrm{F}_{\text {calculado }}>\mathrm{F}_{\text {tabelado }}\right)$. Isto pode ter ocorrido devido a uma boa repetibilidade dos pontos centrais, ou seja, quando o erro puro é muito inferior à falta de ajuste.

A Figura 1 mostra as superfícies de resposta geradas através dos modelos propostos, considerando-se os pontos médios de concentração de pectina e fibras. De acordo com as figuras, as espessuras e PVAs foram obtidas nas menores concentrações de fibras. Assim, a partir do estudo posposto neste artigo, foi possível selecionar concentrações otimizadas para serem utilizadas em estudos posteriores, que são: $9 \mathrm{~g}$ de pectina/ $2 \mathrm{~g}$ de fibras e 5 gramas de pectina/0,5 gramas de fibras.

Figura 1 - superfícies de resposta para: espessura, PVA.
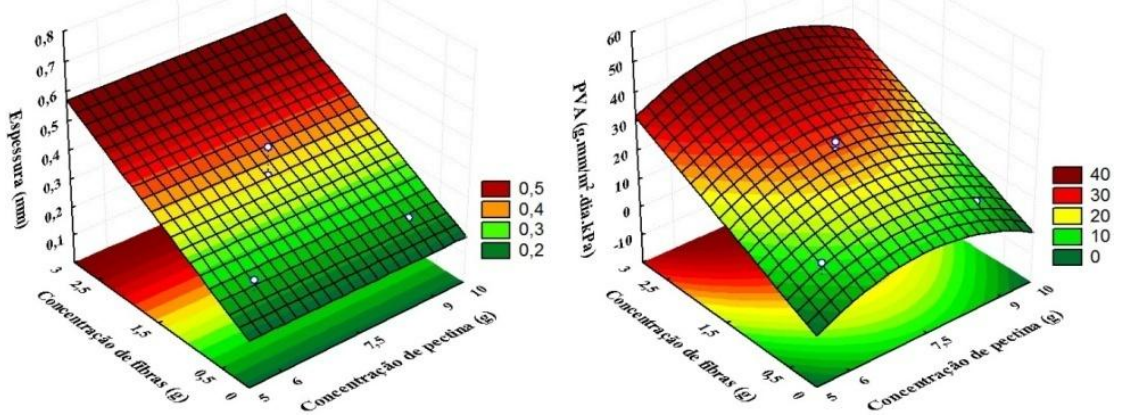

\section{CONCLUSÕES}

Nota-se, a partir dos resultados obtidos, que a adição das fibras de coco-da-baía aos biofilmes propiciou diminuição da solubilidade e resultados moderados para permeabilidade a vapor de água. A partir da análise estatística foi possível determinar concentrações ótimas de $9 \mathrm{~g}$ de pectina/2 $\mathrm{g}$ de fibras e 5 gramas de pectina/0,5 g de fibras. Análises subsequentes podem ser feitas nestas concentrações para caracterizar o material mais detalhadamente, tendo em vista as suas mais diversas aplicações, como por exemplo, confecção de sacolas e embalagens alimentícias. 


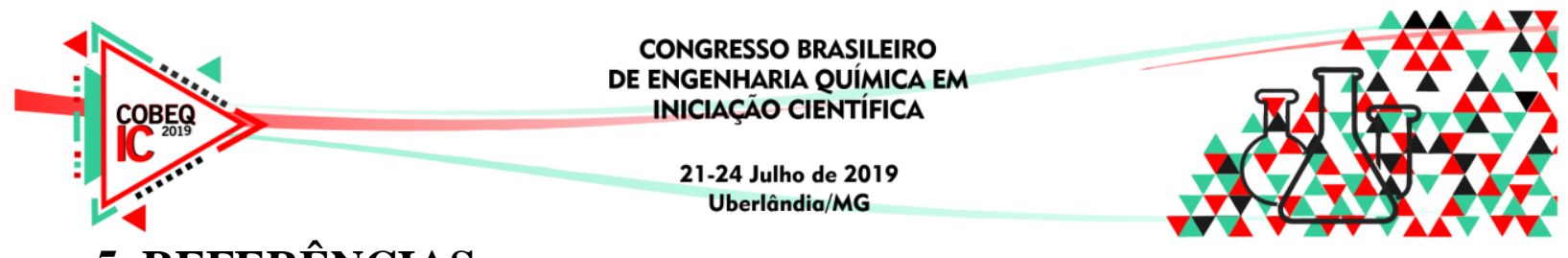

\section{REFERÊNCIAS}

ASTM E96/E96M-16, Standard Test Methods for Water Vapor Transmission of Materials; ASTM International:West Conshohocken, PA, 2016.

HUANG, G. Tensile behaviours of the coir fibre and related composites after $\mathrm{NaOH}$ treatment. Mat. Design, v. 30, n. 9, p. 3931-3984, 2009.

KALIA, S. KAITH, B. S.; KAUR, I. Pretreatments of natural fibers and their application as reinforcing material in polymers compososites - a review. Polym. Eng. Sci., v. 49(7), p. 1253-1272, 2009.

LARA-ESPINOZA, C.; CARVAJAL-MILLÁN, E.; BALANDRÁN-QUINTANA, R.; LÓPES-FRANCO, Y.; RASCÓN-CHU, A. Pectin and pectin-based compocite materials: beyond food texture. Molecules, v. 23, 2018.

LOPES, I.A.; SANTOS JR., J.; DA SILVA, D. C.; DA SILVA, L. J. S.; BARROS, A. K.; VILLA-VÉLEZ, H. A.; SANTANA, A. A. Characterization of pectin biofilms with the addition of babassu mesocarpo and whey protein concetrate. Ameri. Journal Mat. Sci, v. 7(3), p. 64-70, 2017.

MACHADO, B. A. S.; REIS, J. H. O.; DA SILVA, J. B.; CRUZ, L. S.; NUNES, I. L.; PEREIRA, F. V.; DRUZIAN, J. I. Obtenção de nanocelulose da fibra de coco verde e incorporação em filmes biodegradáveis de amido plastificado com glicerol. Quim. Nova, v. 37, n. 8, p. 1275-1282, 2014.

NGO, T. M. P.; DANG, T. M. Q.; TRAN, T. X.; RACHTANAPUN, P. Effects of zinc oxide nanoparticles on the properties of pectin/alginate edible films. Int. Journal Polym. Sci., v. 2018, p 1-9, 2018.

ORTIZ, C. M.; SALGADO, P. R.; DUFRESNE, A.; MAURI, A. N. Microfibrillated cellulose addition improved the physicochemical and bioctive properties of biodegradable films based on soy protein clove essential oil. Food. Hydroc., v. 79, p. 416-427, 2018.

RHIM, J.W.;GENNADIOS, A.;WELLER, C.L.;HANNA, M. A. Sodium dodecyl sulfate treatment improves properties of cast films from soy protein isolate. Indust. Crops Prod., v. 15, n. 3, p. 199-205, 2002.

ROSA, M. F.; MEDEIROS, E. S.; MALMONGE, J. A.; GREGORSKI, K. S.; WOOD, D. F.; MATTOSO, L. H. C.; GLENN, G.; ORTS, W.J.; IMAM, S. H. Cellulose nanowhiskers from coconut husk fibers: effect of preparation conditions on their thermal and morphological behavior. Carb. Polym., v. 81, p. 83-92, 2010.

SANTANA, A. A., KIECKBUSCH, T. G. Physical evaluation of biodegradable films of calcium alginate plasticized with polyols. Braz. Journ. of Chem. Eng., v. 30, p. 835-845, 2013.

SEIXAS, F. L.; TURBIANI, F. R. B.; SALOMÃO, P. G.; SOUZA, R. P.; GIMENES, M. L. Biofilms composed of alginate and pectin: effect of concentration of crosslinker and plasticizer agents. Chem. Eng. Tran., v. 32, p. 1693-1698, 2013.

SILVA, M. A., BIERHALZ, A. C. K., KIECKBUSCH, T. G. Alginate and pectin composite films crosslinked with $\mathrm{Ca} 2+$ ions: Effect of the plasticizer concentration. Carb. Polym., v. 77(4), p. 736-742, 2009. 